\title{
BIODEGRADABLE ZINC ALLOYS AND COMPOSITES FOR BIOMEDICAL APPLICATION: AN OVERVIEW OF PROCESSING ROUTES AND POSSIBLE FUTURE WORK
}

\author{
Maruf Yinka KOLAWOLE ${ }^{*}$, Jacob Olayiwola AWEDA², Sulaiman ABDULKAREEM ${ }^{2}$ and \\ Sefiu Adekunle BELLO ${ }^{3}$
${ }^{1}$ Kwara State University, College of Engineering \& Technology, Department of MechanicalEngineering, Malete, Nigeria
${ }^{2}$ University of Ilorin, Faculty of Engineering \& Technology, MechanicalEngineering Department, Nigeria ${ }^{3}$ Kwara State University, College of Engineering \& Technology, Department of MaterialScience and Engineering, Malete, Nigeria

\begin{abstract}
Biodegradable metallic implants are revolutionized alternative materials currently being considered for orthopaedic and stents applications for the restoration and remodeling of defected or fractured hard tissues. Examples of biodegradable metals include magnesium, iron and zinc. Findings had revealed that magnesium and iron show high tendencies of being used as biodegradable metallic implant. However, premature loss of mechanical integrity, high hydrogen gas evolution of magnesium metal as well as slow degradation rate of iron below the clinical benchmark had hindered their applications. On the other hand, Zinc metal with near to ideal degradation rate suitable for orthopaedic application but poor mechanical properties compared to magnesium and iron metals has recently attracted research interest as potential candidate salvager of biodegradable metallic implants. This paper therefore, presents brief review of the current research progress on biodegradable zinc alloys and composites in relation to their processing routes for biomedical application. In addition, key existing and emerging strategies for mechanical properties improvement are highlighted. Processing technique, types and or proportion of alloying elements had been identified as center-hub control for improving mechanical properties of zinc metals. Deductions were made and strategies for further research work on biodegradable zinc alloys were suggested.
\end{abstract}

Keywords: Biodegradable, Metallic implants, Orthopaedics, Zinc alloys, metal matrix composites, Biocompatibility.

\section{Introduction}

Development of new biomaterial in orthopaedic implants for the restoration and correction of defected or fractured human hard and soft tissues are on the increase and has attracted research interest as illustrated in Fig.1. This may probably be as a result of increasing accident rate, diseased bone, old ages and traumatic patientin Nigeria and other parts of the world. These and many more according to Prasad et al [1] constitute the major causes of bone fractures with other associated health risks. It usually leads to life difficulty and may cause total breakdown of patients'mobility. The advancement in technology, as well as the patient desire to maintain the same level of activity and quality of life has really boosted the bio-implant market (Fig.1.) resulting in demand increase for high-performance implantable biomaterials that can address unique challenges in orthopaedics, vascular therapy, trauma, dental and wound care treatment [1]. Consequently, the biomaterial market valued at \$94.1 billion USD in 2012 and worth $\$ 134.3$ billion USD in 2017 with a specific growth rate of $10.3 \%$ [1], [2]. By this rate of growth, bioimplant market is expected to reach $\$ 175.8$ USD billion by 2020 . Orthopaedic biomaterials in 
form of internal implant are often used as remedies to structurally remodel, reconstruct and rehabilitate affected patients' bone [3]-[5].

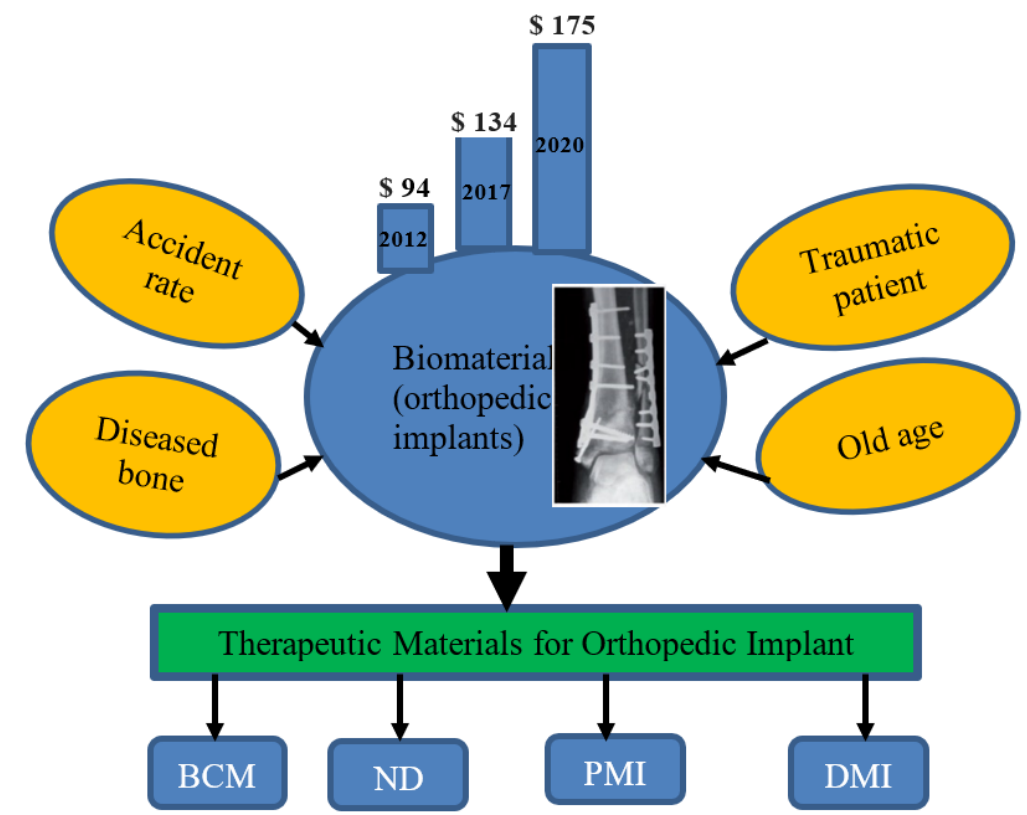

BCM: Bio-ceramic material implant PMI: Polymeric materialImplant

NDMI: Non-Biodegradable Metallic implant DMI: Biodegradable Metallic Implant

Fig. 1. Biomaterial growth rate and therapeutic materials for orthopedic implant

Conventional technique of osteosynthesis of the above complications usually involved the use of traditional bio-inert metallic materials including CoCrMo, Titanium, tantalum, gold and stainless-steel alloys [6] in the form of permanent bone plates and screws. This class of metallic implants has high corrosion resistance property and hence remain stable in ph ysiological environments and therefore use as permanent metallic implants (PMI) in patients [7]-[9]. PMI are characterized by high elastic modulus of about $(200 \mathrm{GPa})$ which is far much higher than that of human natural bone ( $45 \mathrm{GPa}$ ) [4]. When this is implanted in the body, it carries most loads thereby denying the host healing tissue of its normal loads resulting in bone weight loss and weakening due to impaired stimulus caused by stress shielding effect. In sort, the consequence of permanent presence of this type of implant can results in chronic inflammatory response due to possible release of metallic ions from the implant whenever there is defect in surface oxides film. Consequently, this defect may undermine the therapeutic function of the device which in most cases require secondary surgery operation for removal of the implant [7], [9]-[12].

Meanwhile, most bone implants in the form of plates, screw, pins, plugs and rods service functions are transient and no longer required after the complete healing process. A novel approach alternative to this nagging challenges is the use of biodegradable or biabsorbable implants. Biodegradable implants permit the growth of new tissue in patient while gradually deteriorating harmlessly in the body at a rate matching the healing kinetics of the diseased bone without abrupt loss in mechanical integrity for complete healing of diseased bones [11], [13][15]. The idea of biodegradation is not new in medical applications and can be traced to biodegradable sutures made of polymeric materials. However, good biocompatibility, bio-safety of corrosion products, superior and stable mechanical strength and biodegradation rate properties of biodegradable metals over the polymeric implants had rendered them a potential candidate in the present-day novel approach of orthopaedic and cardiovascular treatment. 
Biodegradable metals are therefore referred as revolutionizing implant materials and have been extensively studied as the next generation of structural materials for orthopaedic and cardiovascular implants applications in the last two decades [8], [16]-[18]. Up to present, magnesium, iron and zinc base metals and alloys system constitute the newly researched biodegradable metals (BDMs). The driving force for these systems is that they are all intrinsically corrosion susceptible and degrade safely in human body due to essentiality of degraded products in bodily physiological environment that can partake in various metabolic and biological reactions [19]-[21]. The gradual degradation process leads to corresponding gradual loss in mechanical strength which aids in slow transfer of normal load from the implant onto the healing patient bone thereby reducing the stress shielding effect [11].

Magnesium-based alloy system are the most researched among the aforementioned proposed biodegradable metals with large volumes of published on mechanical results, biodegradation, in vitro cy totoxicity, animal testing and clinical trials [14], [16], [22].This can be arrogated to lower elastic modulus of (41-45) GPa closer to that of natural bone (20 45GPa) when compared to either zinc $(90 \mathrm{GPa})$ or iron $(211.4 \mathrm{GPa})$ which are much higher. In addition, the daily intake requirements (240-420) mg per day of magnesium, higher than (8-18) mg per day of iron and (8-11) mg per day of zinc respectively, may be another contributing factor responsible for its being at the vanguard of BDMs research [20], [23]-[25]. However, the unresolvable limitation of magnesium biodegradable metal was to its rapid corrosion rate causing the formation of large amount of hydrogen gas and premature loss of mechanical integrity in bodily fluid during in vitro and/or in vivo degradation process resulting in wound interface cavitation and tissue necrosis [14], [26]. A clinical approach of this limitation suggested the use of syringes soon after implantation in order to diffuse out the generated gas and alleviate the discomfort of the patient [27]. These approaches are with associated health risks.

Consequently, research activities into new alternative biodegradable metals such a s iron and zinc base alloy system as potential BDMs has been on the increase due to the battling challenges of magnesium as biodegradable metal. Iron had good mechanical properties and also biocompatible but ironically degrade very slowly due to its low electrochemical potential ($0.440 \mathrm{~V}$ ) coupled with possible formation of voluminous iron oxide layer which is unsuitable for clinical standard requirement for biodegradable metallic implants [28].

Interestingly, Zinc with electrode potential of $(-0.763 \mathrm{~V})$ has a moderate degradation rate when compared to fast degradation rate of magnesium and the very slow degradation rate of iron in a physiological environment. Zinc is an essential element for human beings considering its nontoxicity at lower rate of degradation with various important physiological roles. It serves as a cofactor in all six classes of enzymes, participates in nucleic acid metabolism as well as gene expression, wound healing, protein regulations and signal transduction body [14], [18], [29]. It is the second most abundant mineral metal element in human body [30] signaling that zinc in human body within the daily recommended allowance is highly beneficial and can easily be metabolized and managed by the body system. Furthermore, the alloying of magnesium with zinc metals in lower and higher proportion for strength enhancement and control of biodegradation of magnesium alloy suggested zinc as a potential biodegradable metal. Moreover, zinc has low melting point $\left(419.6^{\circ} \mathrm{C}\right)$ and less reactive at molten state unlike magnesium, allowing for its easy processing and fabrication in air without requiring a special environment [31]. Considering the beneficial effect of zinc in human lifecycle and moderate degradation rate, it holds a promising future position in biodegradable metal implants especially for osteosynthesis and cardiovascular applications [32].

Recent studies [17], [33], [34] have shown good in vitro and in vivo biocompatibility of zinc base alloys. However, the weak strength (UTS < $20 \mathrm{MPa}$ ), plasticity and low hardness properties constitute a major setback for pure zinc as biodegradable metals [30]. In addition, zinc biodegradation rate is inadequate for most biomedical applications. Therefore, current researches are now been geared towards zinc base biodegradable systems synthesis and fabrication for biomedical applications. 


\section{Bio-metallic Implants}

Historically, bio-metallic implants can be traced down to nineteenth century of iron and gold for body structural support. This development was later favoured and transformed by the successful implementation of Lister's aseptic surgical technique in $1860 \mathrm{~s}$ to have become a predominant implant material in today's orthopaedic surgery, cardiovascular stents, dental and orthodontic practices applications [35]. Although, polymeric and ceramics materials had been known and used as medical implants over a long time [36]. However, metallic implant is often considered over polymer, ceramics, and ceramic or polymer composites materials especially in load bearing application due to its high mechanical strength and fracture toughness close to natural human bone [37]. The primary role of metallic implants is to provide permanent or temporary supports for the ailing or fractured bone. The earlier used criteria for the selection of bio-metallic implant materials was mainly based on biocompatibility and mechanical strengths. This yardstick qualified stainless steels, cobalt, titanium, nickel and tantalum-based alloys as the early and first sets of bio-metallic implants [8], [37]. These implants remained permanently in the bodily fluid even after the healing of the fractured or damaged bone due to insignificant deterioration or high corrosion resistance and inertness to the host tissue. As such, their stiffness/strength remains the same "non-biodegradable metallic implants" with consequence effect of stress shielding unlike biodegradable metals that degrade steadily (loss in strength) at a pace matching the regaining strength of the new healing bone as schematically illustrated in Fig. 2 as adapted from Ding [38]. Consequently, there is possibility of metal ion releasing into the surrounding host tissue over a long time due to possible defect that may occur in the surface oxide film since there is no material with ideal inertness. This defect may adversely affect the healing process and cause chronic inflammatory at host tissue site [10], [39]. Moreover, they are characterized by high elastic modulus which is responsible for the implant carrying the whole load causing stress shielding and decalcification effects which is deleterious to the healing bone [39]. These consequences always resulted in re-surgical operation for corrective measure with associated financial implication and extra pains to the patient. These burdens had necessitated research activities into biodegradable metallic implants.

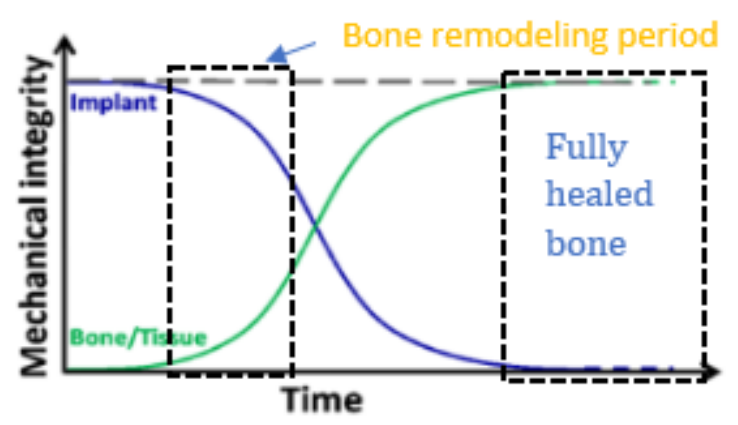

Fig. 2. Mechanical property matching between new bones and implants, adapted from Ding [38]

Biodegradable metallic materials are thus fast becoming an alternative bio-implants for the reconstruction and modelling of diseased and/or damaged bone in lieu of inert conventional metallic implants. This is due to close-to- match mechanical properties of these metals with natural bone and ability to undergo degradation process harmlessly with the host tissue [16]. In addition, this class of bio-implants enhance a beneficial interaction by circumventing the pains bored by patient during re-surgical operation. Promotion of Osseo-integration of the new bone, supplied of mineral nutrient for metabolic activities and strong bonds interface at the implant sites are among other benefit. The mechanism behind the degradation process involves the release of 
electron when the metal is immersed or subjected to a physiological environment to become positively charge ion. The more tendency of a metal to loosen electron to form its ions more than hydrogen, the more electropositive a metal is and the more negative is its standard electrode potential becomes. From the knowledge of electrochemistry perspectives, the magnitude of negative standard electrode potential constitutes an important criterion in determining the degradation properties of a metal in a particular media. Cheng et al [40] asserted that, the more the magnitude of negative standard electrode potential, the higher the degradation tendency of such a metal. The most recognized metals of biodegradable metals are magnesium, iron and zinc with $-2.37,-0.44$ and $-0.763 \mathrm{~V}$ standard electrode potential respectively [22], [40].

Consequently, the attractiveness of biodegradable metallic implants in biomedical application was due to its excellent tunable mechanical properties similar to conventional metallic implants, good degradability and biocompatibility [25], [41]. It eliminates the extra cost and pains usually bored by patient with conventional implants during the course of second-surgical operation. The elastic modulus and mechanical strength of biodegradable metals have a close match with the natural bones. The degradation feature is a double edge sword in that, it provides a source for body mineral elements and gradual relief and/or transfer of load from implant to the host tissue as it degrades. Thus, eliminating stress shielding effect during healing periods. Despite the vast research activities over the years coupled with interesting properties of magnesium and iron as biodegradable metallic implants, rapid degradation and high hydrogen gas evolution are still major sense of concerns [42], [43] which had limited their application.

Zinc is the newest member of biodegradable metallic implant family introduced in 2013 as potential bio-metallic candidate due to its tailorable biodegradability and biocompatibility properties [44]. As a result, efforts are on-going to improving its mechanical, biodegradability and bio-functional properties through series of approaches ranging from alloying, composite fabrication and processing techniques. The following are review summaries of recent research activities on the influence of aforementioned approaches on mechanical, degradability and biocompatibility of zinc alloys.

\section{Processing Route and Technique for Property Improvement of Biodegradable Zinc Alloys}

In developing material for a particular application, there is always a present goals of property requirements such materials must possessed for optimum performance in service. By so doing, the influence of processing route and constituting elements on material development cannot be over-emphasized. Similar is the development of biodegradable zinc alloys and composites to meeting the yearning properties requirement in medical industry. This section therefore, provides an outlook for latest processing rou te and various strategies that had been adopted for improvement of properties of zinc alloys.

Li et al [30] reported that incorporation of alloying elements and/or appropriate processing techniques such as special casting, extrusion, rolling, forging and thermal treatments constitute efficient routes through which improvement in mechanical properties can be achieved. It must also be noted that suitable alloying elements that are non-toxic and capable of increasing strength must be carefully selected during synthesis of any implant BDMs. In addition, the processing routes and synthesis of zinc base metal matrix composites (ZMC) can be a promising options form zinc properties improvement for wider applicability in biomaterials.

Metal matrix composites (MMCs) has gain wide applications in automotive, aerospace and structural applications owing to superior mechanical (strength, wear, hardness, fatigue resistance) and corrosion control. The advantage of using MMCs as biomaterials was the easy tailoring of material properties for specific or desired requirement applications. This can be achieved through appropriate selection of suitable composites constituent elements and processing technique [45], [46]. Till now, volumes of most reported works on biodegradable zinc-based alloys were done 
through casting technique with one or two thermal treatments (extrusion, rolling) for further processing [18], [30], [47]-[49].

Powder metallurgy technology of metal is a promising processing route that is continually and rapidly growing for processing of various shapes of metal alloys and composites. It is a high precision metal forming route resulting in near net pieces, cutting-off the extra cost of machining as experienced in the case of casting technique [50]. One chief advantage of this technique was flexibility giving room for easy tailoring of product properties to suit a specific application. Considering the dynamic parameters of material properties as clinically required, Powder metallurgy glow-out as a promising technique for the processing of biodegradable metals. Until present, work on powder metallurgy processing of biodegradable zinc alloys are rarely found in literature and are limited. Apart from the recent work of Krystýnová et al., Bagha et al., and Kolawole et al., [51], [52][53] on characterization of pure zinc and Zn-Mn alloy prepared by powder metallurgy technique, no other work has been found on zinc base alloys to the best of the author's knowledge. Findings from their works show that PM is a promising technique for the processing of zinc biodegradable metals. This review therefore tends to present the progress report and limitation where necessary on biodegradable zinc alloys to providing a basis for further research on the new development.

\section{Influence of Alloying and Thermal Treatment on Properties of Binary Zinc Alloy System}

Recent increasing research attention on zinc and its alloys as bio-absorbable metal for biomedical application can best be ascribed to its fairly moderate corrosion rate, ease of processing compared to magnesium and iron, as well as its biological functionality requirement in the body [8], [54]. For instance, biologically, zinc has been confirmed essentially important in about 300 enzymes functioning activities such as for cell proliferation, callus formation, bone protein production enhancement in the human body because it is involved in various aspects of cellular metabolism [55]. Also, Zinc also supports immune functions, protein and DNA synthesis and wound healing. In addition, normal growth and proper sense of taste and smell are supported by zinc. Consequently, the recommended dietary allowance(RDA) and recommended upper limit for zinc are 15 and $40 \mathrm{mg}$ day-1, respectively [56]. The consumption of zinc in amounts higher than these values is generally considered relatively non-toxic, and amounts approaching $100 \mathrm{mg}$ $\mathrm{day}^{-1}$ can be tolerated for some time [56].

Due to above importance, biodegradable zinc metal and its alloys had been proposed for biomedical application for half a decade ago and lots of research works had been done towards improving its mechanical, in vitro and in vivo properties as bio-metallic implants. It has been reported by [47], [57] that, alloying and processing techniques and/or history can have profound impacts on both the mechanical and biological properties of zinc metals. Alloying can be by addition of one element (binary alloy), two elements (ternary alloy) or three or more elements (quaternary alloy) for the purpose of properties enhancements. However, in biomedical field especially in the development of bio-metallic implants, special considerations and attention must be paid to ensuring that alloying elements are bio-safe and non-toxic to the human body. For instance, despite the fact that aluminium is a good alloying element for strength enhancements, it is usually considered unsuitable as alloying elements in biomedical medical materials because it was alleged as neuro toxic, harmful to bone and osteoblasts [58] and linked with Alzheimer and demertia's diseases [59]. For that purpose, researches on bio-metallic implants was mostly on essential body mineral elements. Li et al.,[47] developed biodegradable zinc binary alloys by adding $1 \mathrm{wt} \%$ of magnesium, calcium and strontium as alloying element in zinc via casting technique. The results of their investigation showed an improved mechanical and biocompatibility properties with $\mathrm{Zn}-1 \mathrm{x}$ (where $\mathrm{x}=\mathrm{Mg}, \mathrm{Ca}$ and $\mathrm{Sr}$ ) alloys. The outcome of the $\mathrm{In}$ vitro and In vivo assessment of $\mathrm{Zn}-1 \mathrm{x}(\mathrm{Mg}, \mathrm{Ca}$ and $\mathrm{Sr})$ revealed a very low $(<0.2 \%)$ hemolysis rate which was considered safe according to ISO 10993-4:2002. In addition, results of the in vivo 
properties evaluation of the alloys promote the viability and proliferation of MG63 cells with conclusion that, alloying zinc with nutrient $1 \% \mathrm{wt} \mathrm{Mg}, \mathrm{Ca}$ and $\mathrm{Sr}$ can enhance the biological compatibility of zinc alloys with high potential for use as biodegradable metals. Similar ternary zinc-based alloy was reported by Li et al., [47] zinc based ternary alloys were prepared with $1 \%$ wt of strontium, calcium and magnesium using die casting technique followed by hot-rolling and extrusion processes on the as-cast die samples. The microstructure, mechanical properties, corrosion behaviour, hemocompatibility and cytocompatibility of the ternary $\mathrm{Zn}-1 \mathrm{Mg}-1 \mathrm{Ca}, \mathrm{Zn}$ $1 \mathrm{Mg}-1 \mathrm{Sr}$ and $\mathrm{Zn}-1 \mathrm{Ca}-1 \mathrm{Sr}$ alloys were systematically examined. It was reported that, the mechanical properties of the ternary alloys were much higher than that of pure zinc due to alloying effects of the nutrient elements and thermal treatments. The results further revealed that, the addition of the nutrient elements $(\mathrm{Mg}, \mathrm{Ca}$ and $\mathrm{Sr}$ ) guarantee the bio-safety of the new zinc based biodegradable implants due to enhanced acceptable hemocompatibility and cy tocompatibility test results. Similar investigation was carried out by Kubásek et al., [60] on $\mathrm{Zn}-0.8 \mathrm{Mg}$ and Zn- $1.6 \mathrm{Mg}$ using magnesium based WE43 alloy as control. All sample were processed through the same route. The sample were die-cast and hot extruded using hydraulic press at an extrusion ratio of 10:1 and $2 \mathrm{~mm} / \mathrm{min}$ speed to produce a diameter of $6 \mathrm{~mm}$ under extrusion temperatures of 300 and $400{ }^{\circ} \mathrm{C}$ for zinc and WE43 alloys respectively. The microstructure, mechanical and corrosion properties as well as In vitro biocompatibility was examined. It was reported that the hot extruded $\mathrm{Zn}-0.8 \mathrm{Mg}$ alloy possess the best combination of tensile strength (301 MPa) and plasticity of $15 \%$ among all the examined zinc-based alloys which meet the general requirements defined for biodegradable implants. They further asserted that lower corrosion rate of $\mathrm{Zn}-0.8 \mathrm{Mg}$ alloy compared with WE43 alloy can ensure an optimum load bearing capacity without loss of integrity for 6 weeks. The authors also reported that zinc alloys were less biocompatible compared with WE43 alloy even though still within the acceptable ranges with no evidence of genotoxicity and mutagenicity detected in all the samples investigated.

Based on the above results, alloying and types of thermal treatment on zinc-based alloys influenced its properties. However, the magnitude of these influence varies with the types of alloying elements and thermal treatment employed. Dambatta et al., [61] investigated the influence of homogenous thermal treatment on the microstructure, mechanical and degradation properties of $\mathrm{Zn}-3 \mathrm{Mg}$ alloy as potential implant material. The $\mathrm{Zn}-3 \mathrm{Mg}$ alloy samples were prepared by die casting technique. The molten metal was poured at $500{ }^{\circ} \mathrm{C}$ into preheated iron die at $150{ }^{\circ} \mathrm{C}$ and homogenized in vacuum furnace at $360^{\circ} \mathrm{C}$ for $15 \mathrm{hrs}$ soaking time. Results of their studies show that homogenization of $\mathrm{Zn}-3 \mathrm{Mg}$ alloys dissolved the observed dendritic structure in as-cast specimen with reduction in the casting defect. Also, an increase in corrosion resistant of the homogenized alloy was noticed and attributed to homogenous distribution of phases within the microstructure with reduction in casting defect. However, a slight reduction on the mechanical (micro-hardness, tensile strength) properties with corresponding increase in ductility was reported. Effect of lower concentration of magnesium (less than $0.1 \% \mathrm{wt}$ ) as alloying element in zinc on mechanical properties improvement for stent application was experimentally determined and found in the literature [36], [62]. The effect of thermal and cold work treatments on as-diecast $\mathrm{Zn}-\mathrm{Mg}(<0.1 \%$ wt $\mathrm{Mg})$ alloy was carried out and reported in the work of Jin et al., [62]. The die cast ingot prepared under a vacuum furnace melting and solidified in a stain less steel was extruded at $150{ }^{\circ} \mathrm{C}$ to $13 \mathrm{~mm}$ diameter. The $13 \mathrm{~mm}$ diameter rod was finally drawn into $0.25 \mathrm{~mm}$ diameter wire followed by microstructure, mechanical properties and In vivo study characterization. The outcomes of their investigation show a decrea sing trend in average grain size with increase magnesium content accompanied by a corresponding increase in tensile and elongation properties of extruded and as-die cast drawn $\mathrm{Zn}-\mathrm{Mg}$ alloy. The alloy with maximum $\mathrm{Mg}$ addition was reported to have maximum mechanical properties and is also characterized with high corrosion resistance properties. One major deduction from their work was that, mechanical and corrosion properties $\mathrm{Zn}-\mathrm{Mg}$ alloys increased with increasing magnesium content, although the maximum limit of $0.08 \% \mathrm{wt}$ of $\mathrm{Mg}$ was examined in their work. Further search on the 
influence of magnesium as zinc alloying element at higher amount was traced to the work of Kubásek et al., [36]. In their work, $\mathrm{Zn}-\mathrm{Mg}(\mathrm{Mg}=0.8-8.3) \%$ wt die cast alloy was prepared and mechanical (micro-hardness, compressive, bending and tensile) properties was evaluated. Indirect contact cytotoxicity of Zn-0.8 extract investigation using human osteosarcoma cell (U-2 OS) was carried out as well. It was found that, the maximum tensile and compressive strengths of 170 and $320 \mathrm{MPa}$ respectively were obtained at $0.8 \% \mathrm{wt}$ of $\mathrm{Mg}$ in zinc with highest elongation of $2 \%$. It was reported that the cytotoxicity of $\mathrm{Zn}-0.8 \mathrm{Mg}$ alloy was low though slightly higher than that of pure magnesium.

In a related work by Levy et al., [55], mechanical, biodegradation and biocompatibility of binary and ternary alloys of zinc metal was investigated through die casting of $\mathrm{Zn}-1 \mathrm{Mg}$ and $\mathrm{Zn}-1 \mathrm{Mg}-0.5 \mathrm{Ca}$ alloys. It was reported that $\mathrm{Zn}-1 \mathrm{Mg}-0.5 \mathrm{Ca}$ ternary alloy had higher strength, hardness and corrosion rate in air and phosphate buffer solution (PBS) environment relative to the $\mathrm{Zn}-1 \mathrm{Mg}$ binary alloy. The increase in mechanical properties of ternary alloy over binary alloy was attributed to a decrease in zinc dendritic average size due to the addition of Ca while corrosion rate increase was credited to the formation of active $\mathrm{CaZn}_{13}$ phase in the eutectic zone which supported micro-galvanic corrosion over the $\mathrm{Mg}_{3} \mathrm{Zn}_{11}$ intermetallic phase of binary alloy in the surface oxide film. The cytotoxicity examination of both alloys indicated that their biosafety is adequate for use as biodegradable metals for biomedical application.

The increasing use of magnesium as alloying element in biodegradable zinc alloys can be juxtaposed by the fact that apart from enhancing the strength it can also promote the bioactivity of the implant. This is possible by inducing the formation of bone-like biocompatible corrosion products such as hydroxyapatite and brucite during degradation. The formation of these products is very pertinent to bone osteointegration and healing process. Alves et al., [48] carried out an In vitro degradation of $\mathrm{Zn}-\mathrm{Mg}$ alloy under physiological simulated conditions with $\mathrm{Zn}-\mathrm{xMg}(\mathrm{x}=0$, 1 and 2) cast alloys using $\mathrm{ZnCl}_{2}$ as flux. The built-up corrosion product of the degradation was studied using simulated body fluid (SBF) media as the physiological environment by confocal Raman spectroscopy, scanning electron microscopy and energy-dispersive X-Ray spectroscopy. The results of the investigation revealed that the incorporation of magnesium as alloying element in zinc can aid the formation of brucite, skorpionite and hydroxyapatite which are very vital for bone regeneration. In an effort to mimic the process occurring In vivo which may serve as appropriate model to In vivo testing, the corrosion rate and cytocompatibility of surface pretreatment of a novel biodegradable $\mathrm{Zn}-1.5 \mathrm{Mg}$ alloy was studied by Jablonská et al., [63]. In their study, the $\mathrm{ZnMg}$ alloy sample was incubated in SBF at $37{ }^{\circ} \mathrm{C}$ for 14 days for the surface pretreatment. Then, the corrosion rate determination, direct and indirect cytocompatibility test technique of both surface and non-surface pre-treatment of the alloy sample was examined. Outcomes of their investigation revealed that surface pre-treatment decreased the corrosion rate. Meanwhile, the cytocompatibility properties of $\mathrm{Zn}-1.5 \mathrm{Mg}$ alloy was high when conducted via indirect technique over the direct method. The elemental analy sis of the corrosion built-up layers was characterized by high $\mathrm{Ca}$, and $\mathrm{P}$ deposits which can be presumed responsible for the decrease in corrosion rate and high cytocompatibility.

\section{Effect of other Alloying Elements on Properties of Zinc Based Alloys for Biomedical Application}

Most research interest has been focused on pure $\mathrm{Zn}$ and $\mathrm{Zn}$ alloyed with nutrient elements like $\mathrm{Mg}$ and $\mathrm{Ca}$ [47], [48]. Unfortunately, other alloying elements such as aluminium, copper and bismuth which were considered harmful when added in excess were sparsely investigated compared to the nutrient elements. For instance, excess addition of aluminum was reported being toxic to neuron [64]. However due to the alloying power potential "of these so called other alloying elements" in mechanical properties improvement, they had been mostly investigated in lower concentration in Zinc for potential application in biomedical applications. 
Niu et al., [65] investigated the effect of $4 \mathrm{wt} \%$ of $\mathrm{Cu}$ in $\mathrm{Zn}$ potential vascular stents application. The as-cast $\mathrm{Zn}-\mathrm{Cu}$ alloys was preheated at $553 \mathrm{~K}$ and extruded at extrusion ratio of 9:1 and $2 \mathrm{~mm} / \mathrm{min}$ speed. Mechanical properties and degradation as well as cytotoxicity antibacterial effects of copper as alloying elements was reported. Results of the investigation revealed that, the yield strength, ultimate strength and elongation of $250 \pm 10 \mathrm{MPa}, 270 \pm 10 \mathrm{MPa}$ and $51 \pm 2 \%$, were obtained with $9.41( \pm 1.34) \mu \mathrm{m} \mathrm{year}^{-1}$, corrosion rate and with acceptable toxicity level to human endothelial cells as required in vascular stents application.

Reporting the influence of copper addition $(0,1,2,3$ and 4$) \mathrm{wt} \%$ on homogenized hot extruded $\mathrm{Zn-xCu}$ alloys, Tang et al., [66] concluded that, tensile test indicates that cu as alloying element in zinc could significantly improve the mechanical properties with elongation of $51 \%$ of $\mathrm{Zn}-\mathrm{xCu}$ alloys which could facilitate the processing of micro-tube stent application. Endothelial and antibacterial properties of $\mathrm{Zn}-\mathrm{xCu}$ alloys at a concentration greater than $2 \mathrm{wt} \%$ was perfect.

Similar work of Tang et al., ) [67] examined the effect of varying amount of magnesium (wt\%) on the earlier prepared $\mathrm{Zn}-3 \mathrm{Cu}$ alloy. The as-cast $\mathrm{Zn}-3 \mathrm{Cu}-\mathrm{xMg}(\mathrm{x}=0,0.1,0.5$ and 1.0) wt\% was homogenized at $360{ }^{\circ} \mathrm{C}$ for $3 \mathrm{hrs}$ and then quenched in water. It was further hot extruded at $280{ }^{\circ} \mathrm{C}$ using extrusion ratio and speed of 9:1 and $2 \mathrm{~mm} / \mathrm{s}$. Results obtained showed that, the yield strength was improved from 213.7 to $426.7 \mathrm{MPa}$ with an equivalent increase of $99.7 \%$ while elongation decreased from $47.1 \%$ to $0.9 \%$. Besides, biocompatibility was enhanced apparently and in vitro corrosion rates increased from 11.4 to $43.2 \mu$ year $^{-1}$, which is more suitable for clinic application.

Aluminium is among the other alloying elements for zinc-based alloys that had been studied and reported. Though, it has been considered as bio-risky element with associated health challenges including neuro toxic, initiating Alzheimer's diseases and among others. However, Bowen et al.,[49] argued convincingly that, there has been no strong scientific evidence per se supporting the presumed theory based on their long search of literatures and conferences discussions. In line with this assertion, Bakhsheshi-Rad et al., [68] had also reported that the small amount of aluminium released continuously throughout the degradation process can be tolerable. In their own work, $\mathrm{Zn}-0.5 \mathrm{Al}$ binary alloy and $\mathrm{Zn}-0.5 \mathrm{Al}-\mathrm{xMg}$ ternary alloy system was investigated to evaluate the mechanical properties, corrosion behaviour, cytotoxicity and antibacterial activities. The results showed that tensile and micro-hardness properties of $\mathrm{Zn}$ $0.5 \mathrm{Al}-\mathrm{xMg}$ ternary alloy system was higher that the $\mathrm{Zn}-0.5 \mathrm{Al}$ binary alloy and it increases with increasing magnesium content. The maximum tensile and micro-hardness value was obtained at higher amount of magnesium content i.e, $\mathrm{Zn}-0.5 \mathrm{Al}-\mathrm{xMg}(\mathrm{x}=0.5 \mathrm{wt} . \%)$. Degradation results indicated that $\mathrm{Zn}-0.5 \mathrm{Al}$ had the highest degradation rate compared with the ternary alloy. The cytotoxicity and antibacterial tests revealed that $\mathrm{Zn}-0.5 \mathrm{Al}-0.5 \mathrm{Mg}$ had the higher viability and antibacterial activities. Similar work was recently published by Bowen et al., [49]. In their work, $\mathrm{Zn}-\mathrm{xAl}$ alloy composition ( $\mathrm{x}=1,3$ and 5$) \mathrm{wt} . \%$ processed via rolling was characterized, mechanically tested and used in arterial implantation in rats for biocompatibility and corrosion rate study. The results of their study concluded that mechanical properties of $\mathrm{Zn}$-xAl rolled alloys are comparable to Co-Cr based alloys with acceptable biocompatibility therefore qualifying $\mathrm{Zn}$ $\mathrm{xAl}$ for stent applications.

Looking at the possibility of modifying the degradation rate of zinc and considering the biosafety and importance of iron requirement in the body, Kafri et al.,[18] investigated the suitability of $\mathrm{Zn}-1.3 \%$ Fe alloy as a biodegradable implant material produced by gravity casting method in both in vitro and in vivo condition. The results from both the in vitro and in vivo studies indicated that the $\mathrm{Zn}-1.3 \% \mathrm{Fe}$ alloy corrosion rate significantly increased compared to pure zinc due to micro-galvanic effects produced by secondary $\mathrm{Zn}_{11} \mathrm{Fe}$ phase. In addition, silver has been as an effective antibacterial element with additional tendency of strength enhancement element when alloyed with zinc. As a result, $\mathrm{Zn}-4 \mathrm{Ag}$ alloy was developed and mechanical characteristic, in vitro degradation, cytotoxicity and antibacterial properties as biodegradable material was evaluated and compared with pure zinc as reported by Li et al., [30]. The developed Zn-4.0Ag alloy was allowed to solidified in graphite mould under vibrating condition forgrain refinement and then homogenized 
at $300{ }^{\circ} \mathrm{C}$ for $1 \mathrm{hr}$ in furnace under argon protective furnace atmosphere and then swaged into $3 \mathrm{~mm}$ diameter wires. The swaged wire further annealed at $390^{\circ} \mathrm{C}$ for 15 minutes, quenched in water and finally precipitated hardened in an oil bath for $10 \mathrm{~min}$ at $100{ }^{\circ} \mathrm{C}$. Results of mechanical and corrosion properties investigation indicated $157 \mathrm{MPa}, 261 \mathrm{MPa}$ and $37 \%$ in yield strength, ultimate strength and elongation respectively with $10.75 \pm 0.16 \mu \mathrm{gcm}^{-2} \mathrm{day}^{-1}$ corrosion rate which were higher than the pure zinc as examined under the same condition. It was also reported that the alloy has acceptable toxicity with effective antibacterial property in vitro.

\section{Powder Metallurgy Processing Techniques for Biodegradable Metals, Alloys and Composite}

Powder metallurgy is a solid- state processing route for the production of near net shape metallic material and devices from metal powders. The compact sample may be obtained by cold or hot isostatic pressing. The hot isostatic pressing technique enhanced densification, reduce porosity and eliminate the sintering steps. Powder metallurgy could also be accomplished via metal injection moulding. This technique tends to be more economical compared with conventional metal processing methods such as casting by reducing the processing steps such as machining, lower energy consumption with higher material utilization. It also allows flexibility of the alloy design with different elemental or ceramic powder addition for better mechanical and bio-functional properties enhancement. Consequently, this method had been employed for the processing of high temperature melting metals such as titanium, nickel, cobalt chromium and their alloys used in biomedical application [69]. Literature search had revealed that, most biodegradable metals researched for biomedical application by casting technique always had mechanical properties below the acceptable clinical standard and as such, usually further beneficiated with one or more of extrusion, rolling, drawing and thermal treatments such as homogenization, annealing and quenching technique [55], [60], [61]. This therefore tends to increase the processing steps with associated cost implications. Studies had however, shown that processing techniques constitute among other factors that can influence the properties and applicability of alloys [14].

Volumes of works had been reported on powder metallurgy processing of biodegradable magnesium and its alloys [70]-[73] to examining one or two powder metallurgy parameters on the selected alloys. Results of early studies by various authors above had showed that powder metallurgy route are governed by a number of processing parameters including the weight fraction of alloying composition, milling time, compaction pressure, heating rate, sintering temperature and time. Čapek and Vojtěch, [70] investigated the effect of compaction pressure on the properties of binary and ternary magnesium alloy using powder metallurgy route. The milling was done for 2 hours with ball to powder ratio of 10:1 under argon atmosphere. The milled powder was compacted with pressure range of $100-600 \mathrm{MPa}$ at a step of $100 \mathrm{MPa}$. Results of the investigation indicated that porosity decreases with increase in compaction pressure with optimum compaction pressure of $400 \mathrm{MPa}$ to obtain the highest densification and mechanical properties. It was also discovered with addition of Manganese in the case of ternary alloy further increased the yield strength and hardness properties than the binary alloys regardless of the compaction pressures. In a related work, Wang et al.,[71] studied the influence of sintering temperatures on the microstructure, in vitro degradability, mineralization and osteoblast response of magnesium phosphate fabricated using chemical precipitation method. The green compact samples were sintered at 400,600 and $800{ }^{\circ} \mathrm{C}$. The results indicated that densification and crystallinity of the sintered samples increased with increasing sintering temperature. Degradability decreases and bioactivity increases with rise in sintering temperature. They concluded that, the sample sintered at $800{ }^{\circ} \mathrm{C}$ possesses suitable degradability, bioactivities and cytocompatibility properties. 
Metal matrix composites of magnesium alloy matrix had also been investigated via powder metallurgy route. Kowalski et al., [72] reported the effect of hydroxyapatite addition on the properties of mechanically alloyed and sintered $\mathrm{Mg}-\mathrm{RE}-\mathrm{Zr}$ alloy. The milled powder was uniaxially compacted at $600 \mathrm{MPa}$ and sintered $550{ }^{\circ} \mathrm{C}$ for $2 \mathrm{hrs}$ under $10^{-4}$ Torr. The results indicated that there was improvement on mechanical properties with reduction in degradation rate by the formation of protective layer. Powder metallurgy processing route had also been used in the processing of porous metals which may be difficult with other routes. Čapek and Vojtěch, [70] investigated the properties of porous magnesium alloy prepared by powder metallurgy technique. Magnesium powder was manually mixed with ammonium bicarbonate powder and compacted at $265 \mathrm{MPa}$. The compacted sample was deboned at $130{ }^{\circ} \mathrm{C}$ for $4 \mathrm{hrs}$ in muffle furnace followed by sintering at $550{ }^{\circ} \mathrm{C}$ for $6 \mathrm{hrs}$ under argon atmosphere. The outcome of the investigation showed that porous magnesium with $12-38$ porosities can be obtained via powder metallurgy route. The authors also observed magnesium without ammonium bicarbonate had the minimum porosities of 12 with highest flexural strength as compared to porous bio-glass which is currently in use.

Powder metallurgy of biodegradable zinc alloys are rarely found in literature. Until recent when Krystýnová et al., [51] and Bagha et al., [52] work on powder metallurgy processing of pure zinc and $\mathrm{Zn}-\mathrm{Mn}$ alloys respectively, no other work has been found in literature. Krystýnová et al., [51] processed Zinc powders with two different particle sizes $(7.5 \mu \mathrm{m}$ and 150 $\mu \mathrm{m})$ by the methods of powder metallurgy route by adopting the cold pressing, cold pressing plus sintering and hot pressing. Microstructure and the mechanical properties of the prepared samples were assessed with light optical microscope, Vickers microhardness testing and three-point bend testing. Fractographic analysis of broken samples was performed with scanning electron microscopy. The results of the investigation revealed that particle size, compacting pressure have a significant effect on the mechanical properties of pure zinc. Also, the bending properties of prepared materials were positively influenced by compaction pressure and mode of pressing. Samples that were hot-pressed show significant enhancement in the bending and deformation properties as compared with other modes of pressing. Samples compacted at $400 \mathrm{MPa}$ indicated optimum properties with pure zinc prepared from $150 \mu \mathrm{m}$ particle size powder compared to materials prepared from $7.5 \mu \mathrm{m}$ particle size powder. Bagha et al.,[52] also investigated Zn-xMn ( $\mathrm{x}=0,4$ and 24) \%wt alloys by mechanical alloying. The milled, compacted and sintered sample was characterized by density, mechanical properties, corrosion behaviour, cell viability and attachments assessment. Results of the investigation indicated that mechanical alloying of manganese in zinc influences the mechanical and corrosion properties. The best mechanical and corrosion properties reported was obtained at $\mathrm{Zn}-4 \mathrm{Mn}$ with corresponding compressive strength and corrosion rate of $290 \mathrm{MPa}$ and $0.72 \mathrm{~mm} / \mathrm{yr}$ respectively. Cell viability and cell attachment shows the biocompatibility of the alloy and a new suitable biodegradable candidate.

\section{Windows of Opportunities in Processing of Biodegradable Zinc Metals}

The paradigm shift in biodegradable metals has received boosts in zinc metal research [74] due to its moderate biodegradability and excellent biocompatibility properties as well as promising mechanical integrity which deteriorate at the healing pace of bone in bodily fluid over magnesium and iron metals. However, insufficient mechanical properties of pure zinc have been the fundamental limitation of its application in orthopaedic application. But findings from previous studies indicated that a careful selection of material design and processing route for zinc alloys/composites fabrication can annihilates the challenge of its poor mechanical properties. This implies that, there is a green light at the end of the tunnel for commercial clinical acceptability of biodegradable zinc metals for the repair or replacement of damaged or diseased bone. Fig. 3 . illustrates the various windows of opportunities at researchers' disposal that has and/or can be adopted for the processing of a viable clinical required biodegradable zinc. Current literature 
search [54] have shown that exploration of strategies presented in Fig. 3. for the processing of biodegradable zinc are still at their infant stage. The Fig. 3. depicts that, biodegradable zinc can be processed into alloys and composites via casting, powder metallurgy and additive manufacturing techniques plus one or more of thermal or deformation process depending on the form and nature of the staring materials. Evidence from literature revealed that most published work on biodegradable zinc were based on casting techniques plus one or more of thermal and deformation process [75]. In addition, most of these studies were either binary or ternary zincbased alloys. Work on biodegradable zinc-based alloy composites for biomedical application were limited and rarely found in literature. Furthermore, application of powder metallurgy and additive manufacturing routes for the processing of biodegradable zinc alloys and composites were still in the embryonic stage. Meanwhile, exploring the composites of biodegradable zincbased alloy can be another promising option of revamping its metallurgical properties that will be clinically acceptable for orthopaedic application. Thus, as indicated in Fig. 3., the highlighted green boxes indicated opportunities windows that has not or underutilized for the processing of biodegradable zinc alloys and composites. Zinc matrix composite is the metallurgical combination of zinc matrix and reinforcement particles which are usually biocompatible ceramics.

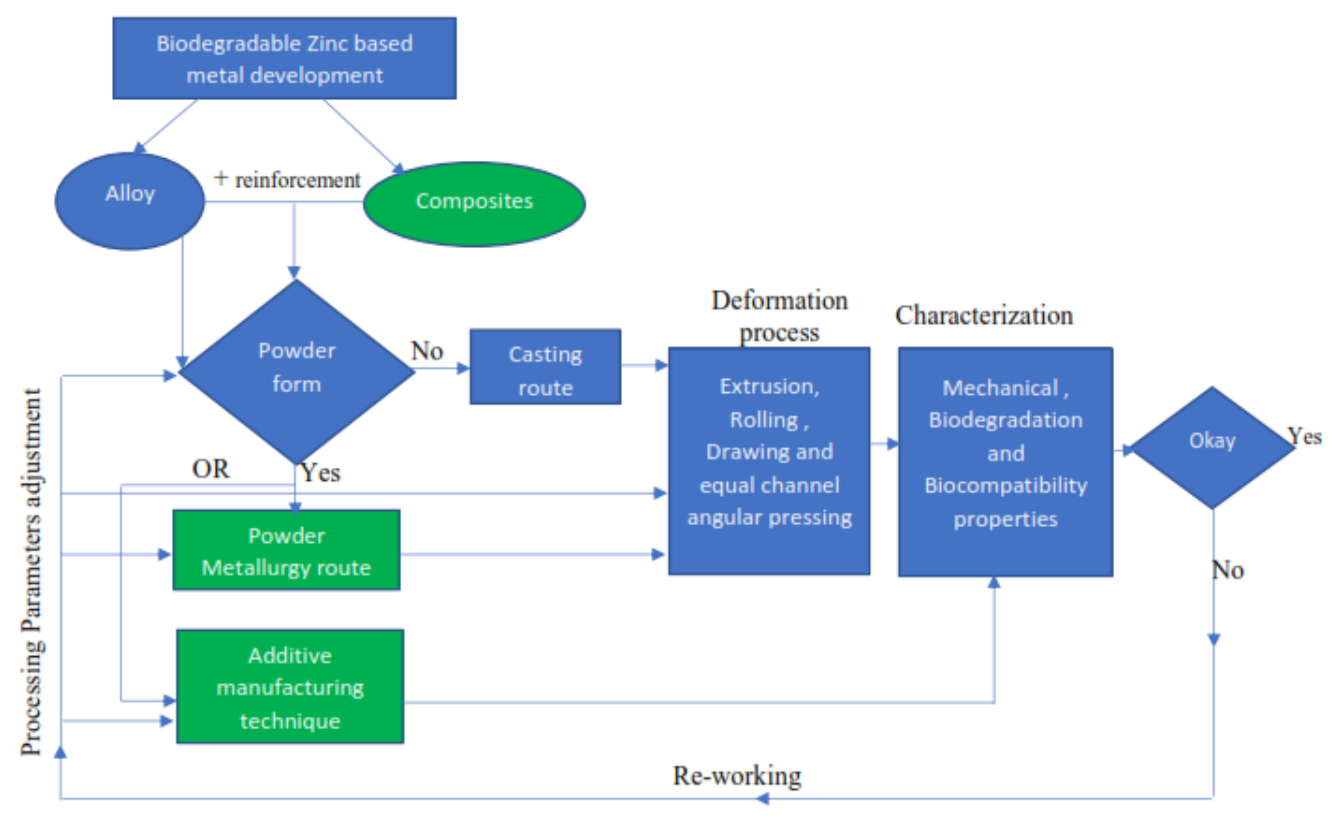

Fig. 3. Windows of Opportunities in Processing of Biodegradable Zinc Metals

A careful selection of this reinforcement stands as a pivotal of tailoring the metallurgical (mechanical and biodegradation) properties of zinc towards desired biomedical application. Furthermore, biocompatible ceramics reinforcements in zinc can be a viable option of improving the bio-functionalities and bioactivities of the resulting composites. However, this is lagging behind considering the volumes of works reported in the literatures. Also highlighted in Fig. 3. is the use of additive manufacturing technique for the preparation of biodegradable zin alloys and composites. This technique provides a total control over the material design because of its flexibilities during usage which allows material to be produced in layers by layer as may be desired by the designer. Although, according to Qin et al., [74] much still need to be learn on this technique if its to be used for preparation of biodegradable alloys and composites due to its low 
melting point. Effective studies on process parameters of this technique by researchers on biodegradable zinc alloys and composites can be of great breakthrough for zinc-based alloys and composites in the field of othorpaedic application.

\section{Conclusions}

A review update on processing of biodegradable zinc-based metals was carried out and the following deductions and suggestions were hereby submitted:

i. Magnesium, iron and zinc constitutes the present biodegradable metals considered for biomedical applications

ii. High degradation rate, high hydrogen evolution and premature loss of mechanical properties of magnesium and its alloys before bone heals up despite series of research attempt, remains a battling challenges in clinical applications

iii. Very slow degradation rate of iron and its alloys unmatched the requirement of orthopedic applications

iv. Zinc metals and its alloys with intermediate degradation rate between magnesium and iron are currently being considered as promising biodegradable materials for orthopedic application. However, mechanical properties still remain a major challenge.

v. The current processing techniques mostly explored in zinc and its alloys usually involved one or more thermomechanical treatment of as-cast samples thereby leading to increasing processing steps and associated cost.

vi. The ternary zinc-based alloys had enhanced the mechanical properties, degradation and biocompatibility properties better than binary zinc-based alloys or pure zinc metal.

vii. Despite the unique advantages of powder metallurgy and additive manufacturing routes of less processing steps and near net shape production, limited work has been found in literature for the processing of zinc alloys and composites.

viii. Limited or no work has been found to the best of authors' knowledge on zinc matrix composites for biomedical application and therefore calls for urgent research revisit towards enhancing and functionalization of zinc strength and biocompatibility properties respectively.

\section{Acknowledgement}

The authors acknowledged "The world Academy of Science (TWAS)" and Interdisciplinary Research Centre on Biomedical Materials, Comsats University, Islamabdad, Lahore Campus for the $\mathrm{Ph} . \mathrm{D}$ Sandwhich research fellowship scholarship during the course of the study.

\section{References}

[1] K. Prasad et al., Metallic biomaterials: Current challenges and opportunities, Materials (Basel)., 10(8), 2017, doi: 10.3390/ma10080884.

[2] M. Prakasam, J. Locs, K. Salma-Ancane, D. Loca, A. Largeteau, and L. Berzina-Cimdina, Biodegradable Materials and Metallic Implants-A Review, J. Funct. Biomater., 8(4), p. 44, 2017, doi: 10.3390/jfb8040044.

[3] D. Arcos et al., The relevance of biomaterials to the prevention and treatment of osteoporosis, Acta Biomater., 10(5), pp. 1793-1805, 2014, doi: 10.1016/j.actbio.2014.01.004.

[4] B. Denkena and A. Lucas, Biocompatible magnesium alloys as absorbable implant materials adjusted surface and subsurface properties by machining processes, CIRP Ann.

- Manuf. Technol., 56(1), pp. 113-116, 2007, doi: 10.1016/j.cirp.2007.05.029. 
[5] X. Li, C. Chu, and P. K. Chu, Effects of external stress on biodegradable orthopedic materials: A review, Bioact. Mater., 1(1), pp. 77-84, 2016, doi: 10.1016/j.bioactmat.2016.09.002.

[6] J. He et al., Advances in Fe-based biodegradable metallic materials, RSC Adv., 6(114), pp. 112819-112838, 2016, doi: 10.1039/C6RA20594A.

[7] G. Katarivas Levy and E. Aghion, Influence of Heat Treatment Temperature on Corrosion Characteristics of Biodegradable EW10X04 Mg Alloy Coated with Nd, Adv. Eng. Mater., 18(2), pp. 269-276, 2016, doi: 10.1002/adem.201500253.

[8] G. K. Levy, J. Goldman, and E. Aghion, The prospects of zinc as a structural material for biodegradable implants - a review paper, Metals (Basel)., 7(10), pp. 1-18, 2017, doi: 10.3390/met7100402.

[9] C. Shen et al., Mechanical properties,: In vitro degradation behavior, hemocompatibility and cytotoxicity evaluation of $\mathrm{Zn}-1.2 \mathrm{Mg}$ alloy for biodegradable implants, RSC Adv., 6(89, pp. 86410-86419, 2016, doi: 10.1039/c6ra14300h.

[10] E. Aghion, G. Levy, and S. Ovadia, In vivo behavior of biodegradable $\mathrm{Mg}-\mathrm{Nd}-\mathrm{Y}-\mathrm{Zr}-\mathrm{Ca}$ alloy, J. Mater. Sci. Mater. Med., 23(3), pp. 805-812, 2012, doi: 10.1007/s10856-0114536-8.

[11] M. Dehestani, E. Adolfsson, and L. A. Stanciu, Mechanical properties and corrosion behavior of powder metallurgy iron-hydroxyapatite composites for biodegradable implant applications, Mater. Des., 109, pp. 556-569, 2016, doi: 10.1016/j.matdes.2016.07.092.

[12] X. Lin, S. Yang, K. Lai, H. Yang, T. J. Webster, and L. Yang, Orthopedic implant biomaterials with both osteogenic and anti-infection capacities and associated in vivo evaluation methods, Nanomedicine Nanotechnology, Biol. Med., 13(1), pp. 123-142, 2017, doi: 10.1016/j.nano.2016.08.003.

[13] A. Y.H., W. S.K., and F. R.J., Pre-clinical in vivo evaluation of orthopaedic bioabsorbable devices, Biomaterials, 21(24), pp. 2635-2652, 2000.

[14] H. Li, Y. Zheng, and L. Qin, Progress of biodegradable metals, Prog. Nat. Sci. Mater.Int., 24(5), pp. 414-422, 2014, doi: 10.1016/j.pnsc.2014.08.014.

[15] M. B. Kannan, C. Moore, S. Saptarshi, S. Somasundaram, M. Rahuma, and A. L. Lopata, Biocompatibility and biodegradation studies of a commercial zinc alloy for temporary miniimplant applications, Sci. Rep., 7(1), pp. 1-11, 2017, doi: 10.1038/s41598-017-15873-w.

[16] Y. F. Zheng, X. N. Gu, and F. Witte, Biodegradable metals, Mater. Sci. Eng. R Reports, 77, pp. 1-34, 2014, doi: 10.1016/j.mser.2014.01.001.

[17] J. Čapek, E. Jablonská, J. Lipov, T. F. Kubatík, and D. Vojtěch, Preparation and characterization of porous zinc prepared by spark plasma sintering as a material for biodegradable scaffolds, Mater. Chem. Phys., 203, pp. 249-258, 2018, doi: 10.1016/j.matchemphys.2017.10.008.

[18] A. Kafri, S. Ovadia, J. Goldman, J. Drelich, and E. Aghion, The suitability of Zn-1.3\%fe alloy as a biodegradable implant material, Metals (Basel), 8(3), pp. 1-15, 2018, doi: 10.3390/met8030153.

[19] F. Witte, The history of biodegradable magnesium implants: A review, Acta Biomater, 6(5), pp. 1680-1692, 2010, doi: 10.1016/j.actbio.2010.02.028.

[20] C. J.Frederickson, J. Y. Koh, and A. I. Bush, The neurobiology of zinc in health and disease, Nat. Rev. Neurosci., 6(6), pp. 449-462, 2005, doi: 10.1038/nrn1671.

[21] W. Jin, G. Wu, H. Feng, W. Wang, X. Zhang, and P. K. Chu, Improvement of corrosion resistance and biocompatibility of rare-earth WE43 magnesium alloy by neodymium selfion implantation, Corros. Sci., 94, pp. 142-155, 2015, doi: 10.1016/j.corsci.2015.01.049. 
[22] Y. Chen et al., Comparative corrosion behavior of $\mathrm{Zn}$ with $\mathrm{Fe}$ and $\mathrm{Mg}$ in the course of immersion degradation in phosphate buffered saline, Corros. Sci., 111, pp. 541-555, 2016, doi: 10.1016/j.corsci.2016.05.039.

[23] P. K. Bowen, J. Drelich, and J. Goldman, Zinc exhibits ideal physiological corrosion behavior for bioabsorbable stents, Adv. Mater., 25(18), pp. 2577-2582, 2013, doi: 10.1002/adma.201300226.

[24] M. Trumbo, P; Schllicker, S;Yates, AA; Poos, Trumbo et al, 2002.pdf, American Dietetic Association, 102(11).pp. 1621-1630, 2002.

[25] A. Purnama, H. Hermawan, J. Couet, and D. Mantovani, Assessing the biocompatibility of degradable metallic materials: State-of-the-art and focus on the potential of genetic regulation, Acta Biomater., 6(5), pp. 1800-1807, 2010, doi: 10.1016/j.actbio.2010.02.027.

[26] A. Celarek et al., PHB, crystalline and amorphousmagnesium alloys: Promising candidates for bioresorbable osteosynthesis implants?, Mater. Sci. Eng. C, 32(6), pp. 1503-1510, 2012, doi: 10.1016/j.msec.2012.04.032.

[27] M. H. Emily Walker, Magnesium, Iron and Zinc Alloys, the Trifecta of Bioresorbable Orthopaedic and Vascular Implantation - A Review, J. Biotechnol. Biomater., 05(02), 2015, doi: 10.4172/2155-952x.1000178.

[28] D. Pierson et al., A simplified in vivo approach for evaluating the bioabsorbable behavior of candidate stentmaterials, J. Biomed. Mater. Res. - Part B Appl. Biomater., 100 B(1), pp. 58-67, 2012, doi: 10.1002/jbm.b.31922.

[29] K. M. Hambidge and N. F. Krebs, Zinc Deficiency: A Special Challenge 1, 2, no. March, pp. 1101-1105, 2018.

[30] P. Li et al., Mechanical characteristics, in vitro degradation, cytotoxicity, and antibacterial evaluation of Zn-4.0Ag alloy as a biodegradable material, Int. J. Mol. Sci., 19(3), 2018, doi: 10.3390/ijms 19030755.

[31] L. F. Guleryuz, R. Ipek, I. Arltman, and S. Karaoglu, Microstructure and mechanical properties of Zn-Mg alloys as implant materials manufactured by powder metallurgy method, AIP Conf. Proc., 1809, 2017, doi: 10.1063/1.4975435.

[32] P. K. Bowen et al., Metallic zinc exhibits optimal biocompatibility for bioabsorbable endovascular stents, Mater. Sci. Eng. C, 56, pp. 467-472, 2015, doi: 10.1016/j.msec.2015.07.022.

[33] L. Zhao et al., Mechanical properties and in vitro biodegradation of newly developed porous Zn scaffolds for biomedical applications, Mater. Des., 108, pp. 136-144, 2016, doi: 10.1016/j.matdes.2016.06.080.

[34] C. Wang et al., Processing of a Novel Zn Alloy Micro-Tube for Biodegradable Vascular Stent Application, J. Mater. Sci. Technol., 32(9), pp. 925-929, 2016, doi: 10.1016/j.jmst.2016.08.008.

[35] Q. Chen and G. A. Thouas, Metallic implant biomaterials, Mater.Sci.Eng. R Reports, 87, pp. 1-57, 2015, doi: 10.1016/j.mser.2014.10.001.

[36] J. Kubásek, I. Pospíšilová, D. Vojtěch, E. Jablonská, and T. Ruml, Structural, mechanical and cytotoxicity characterization of as-cast biodegradable $\mathrm{Zn-xMg}(x=0.8-8.3 \%)$ alloys, Mater. Tehnol., 48(5), pp. 623-629, 2014.

[37] P. Tian and X. Liu, Surface modification of biodegradable magnesium and its alloys for biomedical applications, Regen. Biomater., 2(2), pp. 135-151, 2015, doi: 10.1093/rb/rbu013.

[38] W. Ding, Opportunities and challenges for the biodegradable magnesium alloys as nextgeneration biomaterials, Regen. Biomater., 3(2), pp. 79-86, 2016, doi: 
10.1093/RB/RBW003.

[39] I. Pospíšilová, V. Soukupová, and D. Vojtěch, Influence of calcium on the structure and mechanical properties of biodegradable zinc alloys, Mater. Sci. Forum, 891 MSF, pp. 400-403, 2017, doi: 10.4028/www.scientific.net/MSF.891.400.

[40] J. Cheng, B. Liu, Y. H. Wu, and Y. F. Zheng, Comparative invitro study on pure metals (Fe, Mn, Mg, Zn and W) as biodegradable metals, J. Mater. Sci. Technol., 29(7), pp. 619-627, 2013, doi: 10.1016/j.jmst.2013.03.019.

[41] A. Francis, Y. Yang, S. Virtanen, and A. R. Boccaccini, Iron and iron-based alloys for temporary cardiovascular applications, J. Mater.Sci.Mater.Med., 26(3), pp. 1-16, 2015, doi: 10.1007/s10856-015-5473-8.

[42] L. Li, M. Zhang, Y. Li, J. Zhao, L. Qin, and Y. Lai, Corrosion and biocompatibility improvement of magnesium-based alloys as bone implant materials: A review, Regen. Biomater., 4(2), pp. 129-137, 2017, doi: 10.1093/rb/rbx004.

[43] D. Noviana, D. Paramitha, M. F. Ulum, and H. Hermawan, The effect of hydrogen gas evolution of magnesium implant on the postimplantation mortality of rats, J. Orthop. Transl., 5,pp.9-15,2016, doi: 10.1016/j.jot.2015.08.003.

[44] E. Mostaed, M. Sikora-Jasinska, J. W. Drelich, and M. Vedani, Zinc-based alloys for degradable vascular stent applications, Acta Biomater., 71, pp. 1-23, 2018, doi: 10.1016/j.actbio.2018.03.005.

[45] B. Landkof, Development of high strength magnesium based MMC reinforced with SiC particles for satellite structure applications, Materwiss. Werksttech., 34(4), pp. 395-399, 2003, doi: 10.1002/mawe.200390082.

[46] F. Witte et al., Biodegradable magnesium-hydroxyapatite metal matrix composites, Biomaterials, 28(13), pp. 2163-2174, 2007, doi: 10.1016/j.biomaterials.2006.12.027.

[47] H. F. Li et al., Development of biodegradable Zn-1X binary alloys with nutrient alloying elements Mg, Ca and Sr, Sci. Rep., 5, pp. 1-14, 2015, doi: 10.1038/srep10719.

[48] M. M. Alves, T. Prošek, C. F. Santos, and M. F. Montemor, Evolution of the: In vitro degradation of Zn-Mg alloys under simulated physiological conditions, RSC Adv., 7(45), pp. 28224-28233, 2017, doi: 10.1039/c6ra28542b.

[49] P. K. Bowen et al., Evaluation of wrought Zn-Al alloys (1, 3, and 5 wt \% Al) through mechanical and in vivo testing for stent applications, J. Biomed. Mater. Res. - Part B Appl. Biomater., 106(1), pp. 245-258, 2018, doi: 10.1002/jbm.b.33850.

[50] M. Javanbakht, M. J. Hadianfard, and E. Salahinejad, Microstructure and mechanical properties of a new group of nanocrystalline medical-grade stainless steels prepared by powder metallurgy, J. Alloys Compd., 624, pp. 17-21, 2015, doi: 10.1016/j.jallcom.2014.11.080.

[51] M. Krystýnová, P. Doležal, S. Fintová, M. Březina, J. Zapletal, and J. Wasserbauer, Preparation and characterization of zinc materials prepared by powder metallurgy, Metals (Basel)., 7(10), 2017, doi: 10.3390/met7100396.

[52] P. Sotoudeh Bagha, S. Khaleghpanah, S. Sheibani, M. Khakbiz, and A. Zakeri, Characterization of nanostructured biodegradable $\mathrm{Zn}$-Mn alloy synthesized by mechanical alloying,J.Alloys Compd., 735,pp. 1319-1327, 2018, doi: 10.1016/j.jallcom.2017.11.155.

[53] M. Y. Kolawole, J.O. Aweda, F. Iqbal, A. Ali, and S. Abdulkareem, Mechanical Properties of Powder Metallurgy Processed Biodegradable Zn-Based Alloy for Biomedical Application, Int. J. Mater. Metall. Eng., 13(12), pp. 558-563, 2019.

[54] H. Hermawan, Updates on the research and development of absorbable metals for biomedical applications, Prog. Biomater., 7(2), pp. 93-110, 2018, doi: 10.1007/s40204- 
018-0091-4.

[55] G. Katarivas Levy et al., Evaluation of biodegradable $\mathrm{Zn}-1 \% \mathrm{Mg}$ and $\mathrm{Zn}-1 \% \mathrm{Mg}-0.5 \% \mathrm{Ca}$ alloys for biomedical applications, J. Mater.Sci. Mater. Med., 28(11), pp. 1-11, 2017, doi: 10.1007/s10856-017-5973-9.

[56] L. M. Plum, L. Rink, and H. Hajo, The essential toxin: Impact of zinc on human health, Int. J. Environ. Res. Public Health, 7(4), pp. 1342-1365, 2010, doi: 10.3390/ijerph7041342.

[57] H. Q. Liu, Improving the hemocompatibility of stents, Elsevier Ltd., 2018.

[58] G. Hercz, D. L. Andress, H. G. Nebeker, J.H. Shinaberger, D. J. Sherrard, and J. W. Coburn, Reversal of Aluminum-Related Bone Disease After Substituting Calcium Carbonate for Aluminum Hydroxide, Am. J. Kidney Dis., 11(1), pp. 70-75, 1988, doi: 10.1016/S02726386(88)80179-3.

[59] Dunea G, Mahurkar SD, Mamdani B, and Smith EC, Role of aluminum in dialysis dementia, Ann. Intern. Med., 88, pp. 502-504, 1978.

[60] J. Kubásek, D. Vojtěch, E. Jablonská, I. Pospíšilová, J. Lipov, and T. Ruml, Structure, mechanical characteristics and in vitro degradation, cytotoxicity, genotoxicity and mutagenicity of novel biodegradable Zn-Mg alloys, Mater. Sci. Eng. C, 58, pp. 24-35, 2016, doi: 10.1016/j.msec.2015.08.015.

[61] M. S. Dambatta, S. Izman, D. Kurniawan, S. Farahany, B. Yahaya, and H. Hermawan, Influence of thermal treatment on microstructure, mechanical and degradation properties of $\mathrm{Zn-3Mg}$ alloy as potential biodegradable implant material, Mater. Des., 85, pp. 431437, 2015, doi: 10.1016/j.matdes.2015.06.181.

[62] H. Jin et al., Materials Science \& Engineering C biodegradation, 84(November 2017, pp. 67-79, 2018, doi: 10.1016/j.msec.2017.11.021.

[63] E. Jablonská et al., Influence of surface pre-treatment on the cytocompatibility of a novel biodegradable ZnMg alloy, Mater. Sci. Eng. C, 68, pp. 198-204, 2016, doi: 10.1016/j.msec.2016.05.114.

[64] Y. Liu et al., Study on the in Vitro Degradation Behavior of Commercial $\mathrm{Zn}-4 \% \mathrm{Al}-\mathrm{Sr}$ Alloy for Biomedical Applications, 13, pp. 1640-1655, 2018, doi: 10.20964/2018.02.43.

[65] J. Niu et al., Research on a $\mathrm{Zn}$-Cu alloy as a biodegradable material for potential vascular stents application, Mater. Sci. Eng. C, 69, pp. 407-413, 2016, doi: 10.1016/j.msec.2016.06.082.

[66] Z. Tang et al., Potential biodegradable Zn-Cu binary alloys developedfor cardiovascular implant applications, J.Mech.Behav.Biomed.Mater., 72(March, pp. 182-191, 2017, doi: 10.1016/j.jmbbm.2017.05.013.

[67] Z. Tang et al., Design and characterizations of novel biodegradable $\mathrm{Zn}-\mathrm{Cu}$-Mg alloys for potential biodegradable implants, Mater. Des., 117, pp. 84-94, 2017, doi: 10.1016/j.matdes.2016.12.075.

[68] H. R. Bakhsheshi-Rad et al., Fabrication of biodegradable Zn-Al-Mg alloy: Mechanical properties, corrosion behavior, cytotoxicity and antibacterial activities, Mater. Sci. Eng. C, 73,pp. 215-219, 2017, doi: 10.1016/j.msec.2016.11.138.

[69] M. T. Andani, N. S. Moghaddam, C. Haberland, D. Dean, M. J. Miller, and M. Elahinia, Mechanical Industrial and Manufacturing Engineering , University of Toledo, $2801 \mathrm{~W}$. Bancroft * Communicating author Running Head: New Metals for Bone Implants Short Title : Mandibular Implants For Submission to : Acta Biomaterialia, ACTA Biomater., 2014, doi: 10.1016/j.actbio.2014.06.025.

[70] Č. Jaroslav and D. Vojt, Properties of porous magnesium prepared by powder metallurgy, 33, pp. 564-569, 2013, doi: 10.1016/j.msec.2012.10.002. 
[71] L. Q. Wang, Y. P. Ren, S. N. Sun, H. Zhao, S. Li, and G. W. Qin, Microstructure, mechanical properties and fracture behavior of As-extruded Zn-Mg binary alloys, Acta Metall. Sin. (English Lett., 30(10, pp. 931-940, 2017, doi: 10.1007/s40195-017-0585-4.

[72] K. Kowalski, The Effects of Hydroxyapatite Addition on the Properties of the Mechanically Alloyed and Sintered Mg-RE-Zr Alloy, J. Mater. Eng. Perform., 25(10), pp. 4469-4477, 2016, doi: 10.1007/s11665-016-2306-y.

[73] M. M. Yusof and H. Zuhailawati, The effect of compaction pressure for on properties of binary and ternary magnesium alloys, in AIP Conference Proceedings, 2017, 1865, doi: 10.1063/1.4993339.

[74] Y. Qin et al., Additive manufacturing ofbiodegradable metals: Current research status and future perspectives, Acta Biomater., 98,pp.3-22,2019, doi: 10.1016/j.actbio.2019.04.046.

[75] A. Pola, M. Tocci, and F. E. Goodwin, Review of microstructures and properties of zinc alloys, Metals (Basel)., 10(2), pp. 1-16, 2020, doi: 10.3390/met10020253. 